\title{
EFFECTIVENESS OF GOVERNMENT RESPONSES AND THE ROLE OF NATIONAL CULTURE IN ADDRESSING THE COVID-19 PANDEMIC: A GLOBAL PERSPECTIVE
}

\author{
WALID BAKRY ${ }^{1}$, PETER JOHN KAVALAMTHARA ${ }^{2}$, SAJAN CYRIL ${ }^{3} \&$ YIYANG LIU ${ }^{1}$ \\ ${ }^{1}$ School of Business, Western Sydney University, Australia \\ ${ }^{2}$ UNSW Business School, University of New South Wales, Australia \\ ${ }^{3}$ Australian Institute of Higher Education, Australia
}

\begin{abstract}
The colossal proportion of the COVID-19 disaster, with approximately 213 million confirmed cumulative cases and 4.5 million deaths at the end of August 2021, is of historical significance that is unparalleled. The pandemic has had an impact on the physical, mental and economic welfare of human beings in every corner of the world. To contain the crisis, governments have implemented a set of policies, aimed at directing human behaviour and improving healthcare outcomes almost from the outset, with varying levels of success. The battle against the virus continues. This study utilises data on growth in daily COVID-19 confirmed cases, from 56 countries which were most affected by the pandemic and investigates the effectiveness of several policies implemented by governments. The investigation covers the period, 24 January 2020 to 25 June 2021. The policies analysed in detail constitute 13 containment and health measures, incorporated in the Oxford COVID-19 Government Response Tracker. The research is based on the premise that the contexts in which policies are implemented have a bearing on the outcomes. The contexts are classified under economic status, national culture, the level of human development and population density. We find that these contexts are relevant in determining the success of alternative policy prescriptions. Overall, the containment and health measures are effective in curtailing the growth in COVID-19 cases to varying degrees across all economic contexts of countries. Containment measures are least effective in lower-middle income countries. Three of the six dimensions of Hofstede's national culture classifications tend to be positively associated with infection rates and the other three negatively associated. Moreover, national culture has a more prominent impact on the effectiveness of actions to reduce the growth in COVID-19 cases in lower-middle income countries. It is important to improve effectiveness of government policy responses to combat the pandemic by tailoring them to country-specific contexts. Our findings contribute to this customisation.
\end{abstract}

Keywords: COVID-19, pandemic, OxCGRT, containment and health policies, economic context, Hofstede, national culture.

\section{INTRODUCTION}

The COVID-19 pandemic, which is still a threat to human lives in almost every part of the world, is in its second year. By the end of August 2021, human beings had experienced approximately 213 million cumulative cases of infections and 4.5 million deaths. At the same time the world is also beginning to experience some hope, as the effectiveness of the various government responses to the pandemic are now becoming evident [1]. During February 2020, a joint mission consisting of 25 national and international experts from China, Germany, Japan, Korea, Nigeria, Russia, Singapore and USA led by the World Health Organization began assessing transmission dynamics and control measures. The objective was to enhance understanding, share knowledge and generate recommendations surrounding COVID-19 outbreak [2]. Government responses differed among countries, some choosing a hard lockdown affecting people's mobility and economic performance of the country while others were less restrictive. A ban on public gatherings, travel restrictions and social distancing were the first among certain initiatives undertaken to manage and prevent the rapid transmission 
of the virus [3], [4]. Closing business and imposing bans on gathering have been found effective in reducing COVID-19 transmissions [5]. Strict lockdown and other social distancing policies at a huge cost to the economy during the early days of the pandemic has helped China in drastically reducing infection rate [6].

Oxford COVID-19 Government Response Tracker reports the overall level of government responses to the pandemic in different countries [1]. Fig. 1 shows time varying correlations between growth in total world daily confirmed COVID-19 cases and growth in the worldwide daily average Government Response Index from quarter 12020 to quarter 32021 . Overall, the direction of the relationship between the two metrics was mixed in 2020 but was predominantly negative in the first three quarters of 2021. Therefore, on a global basis, it seems there is an improvement in the effectiveness of government interventions so far in 2021. Countries seem to be getting better at controlling the infections based on lessons learnt in managing the crisis in 2020.

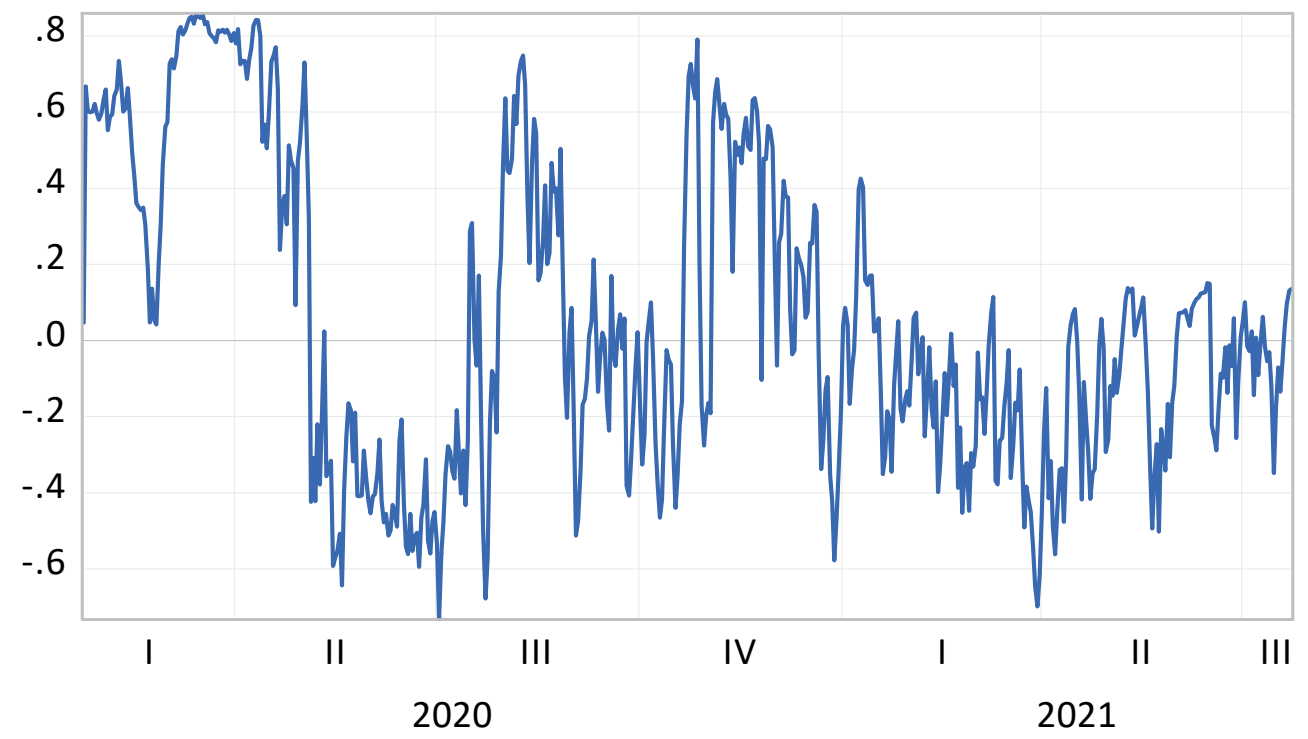

\section{Corr TCCgr_GRIgr}

Figure 1: Time varying correlations (dynamic conditional correlations-GJRGARCH) between growth in total world daily confirmed COVID-19 cases and growth in world average daily Government Response Index [1], [14].

This study presumes that the efficacy of various government containment and health policies and policies to provide income support to citizens in controlling spread of the pandemic may be influenced by economic context, cultural context, level of human development and population density of the individual countries. Less developed countries seem to struggle to respond aggressively to the pandemic as compared to richer countries [7]. To examine social behaviour, scholars have used the framework of Hofstede's cultural dimensions, which are power distance, individualism vs. collectivism, masculinity vs. femininity, uncertainty avoidance, long term orientation vs. short term normative orientation and indulgence vs. restraint [8]. For example, long term orientation vs. short term and 
indulgence vs. restraint seem to have a significant effect on social distancing [6]. A Vietnamese study suggests high power distance, collectivism and uncertainty avoidance help to reduce the spread of COVID-19 [9]. There are mixed results on the effect of population density on the infections. Population density did not affect COVID-19 spread in US and China [10]. However, another study reports a positive relationship between the two variables in both high and low population countries [11]. There is evidence suggesting a positive association between Human Development Index and COVID-19 infections [12], [13].

This paper seeks explanations for differences in effectiveness of government policies to control COVID-19 infections. Our findings reveal important differences in the effectiveness of different policies. A country's economic context, dominant traits of national culture, population density and level of human development critically influence the effectiveness of the policies. The rest of this paper proceeds as follows: Section 2 describes the data. Section 3 presents the research methodology and Section 4 reports the empirical results. Finally, Section 5 concludes the study.

\section{DATA DESCRIPTION}

This study first analysed daily data for the top 70 countries, ranked by number of COVID-19 confirmed cases, for the period from 24 January 2020 to 25 June 2021. Countries with missing data for any of the variables included in this study were excluded. The final dataset used comprises of 56 countries, which account for $90.67 \%$ of cumulative COVID-19 total confirmed cases in the world as of 25 June 2021. These countries are listed in Table 1. The study employs data from four databases. Data relating to COVID-19 policies from Oxford COVID-19 Government Response Tracker (OxCGRT) [1], daily COVID-19 confirmed cases data from Refinitiv DataStream database [14], national culture data from Hofstede Insights [15] and Human Development Index, GNP per capita and population density data from Our World in Data database [16].

Table 1: Sample information. This table displays 56 countries most impacted by COVID19 infections used in this study. The countries are classified into three groups based on their gross national income (GNI) per capita in U.S. dollars [17]. Our sample did not have any lower income countries.

\begin{tabular}{|ll|ll|l|}
\hline \multicolumn{2}{|c|}{$\begin{array}{c}\text { Panel A. } \\
\text { High income countries }\end{array}$} & \multicolumn{2}{c|}{$\begin{array}{c}\text { Panel B. } \\
\text { Upper-middle income countries }\end{array}$} & $\begin{array}{c}\text { Panel C. } \\
\text { Lower-middle } \\
\text { income countries }\end{array}$ \\
\hline Austria & Lithuania & Argentina & Malaysia & Bangladesh \\
Belgium & Netherlands & Azerbaijan & Mexico & Bolivia \\
Canada & Poland & Belarus & Paraguay & Egypt \\
Chile & Portugal & Brazil & Peru & India \\
Croatia & Saudi Arabia & Bulgaria & Romania & Indonesia \\
Czechia & Slovakia & Colombia & Russia & Iran \\
Denmark & Spain & Dominican Republic & Serbia & Morocco \\
France & Sweden & Georgia & South Africa & Pakistan \\
Germany & Switzerland & Iraq & Turkey & Philippines \\
Greece & United Kingdom & Jordan & & Ukraine \\
Hungary & United States & Kazakhstan & & \\
Ireland & Uruguay & Lebanon & & \\
Japan & & & & \\
\hline
\end{tabular}




\section{RESEARCH METHODOLOGY}

To investigate the impact of various government intervention policies on COVID-19 confirmed cases, the study uses the following common static pooled panel ordinary least squares (OLS) model:

$$
T C P_{i t}=\beta_{0}+\beta_{1} \text { GCHIgr }_{i t}+\sum_{c=1}^{C} \beta_{c} X_{c, i}+d_{i}+d_{t}+\varepsilon_{i t} .
$$

where $i$ and $t$ refer to country and time respectively. $T C P_{i t}$ is the dependent variable representing the daily total COVID-19 confirmed cases as a percentage of population for country $i$ and time $t ; \beta_{0}$ is a constant term; GCHIgr $r_{i t}$ is the growth rate in Government Containment and Health Index which reflects governments' containment and health measures to fight COVID-19 spread; $\beta_{1}$ and $\beta_{c}$ are coefficients of the variables under study. $X_{c, i}$ is a set of country-specific explanatory variables (including country's Human Development Index, population density and all six Hofstede cultural dimension indices); $d_{i}$ is a time-invariant unobserved firm-specific effects of the error term; $d_{t}$ is the firm-invariant unobserved time-specific effects of the error term; and $\varepsilon_{i t}$ is the error term. A detailed description of the dependent variable and the eight independent variables in eqn (1) is presented in Table 2.

The study re-estimates eqn (1) by replacing GCHIgr $_{i t}$ with the growth in the Government Economic Support Index $\left(G E S I g r_{i t}\right)$. Estimating these two general models will show if any of these indices influence the number of COVID-19 confirmed cases over time.

The next step is to test the impact of each of the component policies represented by the government policy indices which are identified in the previous step as significantly impacting the number of COVID-19 confirmed cases. This test will be done for the sample of all countries first and then for set of countries classified based on their economic context (that is, high income countries, upper-middle income countries, and lower-middle income countries) [17].

The study uses pooled panel OLS regression model with a robust standard error clustered by country and day (eqn (2)) to assess the relationship between various government intervention policies and COVID-19 confirmed cases:

$$
\mathrm{TCP}_{i t}=\beta_{0}+\sum_{j=1}^{J} \beta_{j} Y_{j, i, t}+\sum_{c=1}^{C} \beta_{c} X_{c, i}+\varepsilon_{i t} .
$$

where $i$ and $t$ refer to country and time respectively. The dependent variable is the daily total COVID-19 confirmed cases as a percentage of population for country $i$ and time $t . Y_{j, i, t}$ is a set of individual country-specific government intervention variables constituting either one or both of the government policy indices (that is, Government Containment and Health Index and Government Economic Support Index) which are found to be significantly related to daily total COVID-19 confirmed cases in the previous step. $\beta_{j}$ and $\beta_{c}$ are coefficients of the variables under study. $X_{c, i}$ is a set of country-specific explanatory variables as described in eqn (1). Table 2 contains detailed descriptions of these variables. The model corrects for potential cross-sectional and serial correlation by clustering the standard errors by country and time.

\section{RESULTS AND DISCUSSION}

Table 3 reports the results of the pooled panel OLS regression analysis (eqn (1)) of the effectiveness of government containment and health measures (Model 1) and the government economic support measures (Model 2) in controlling the spread of COVID-19 for the full set 
Table 2: Variables and definitions [1], [14]-[16].

\begin{tabular}{|c|c|}
\hline Variable & Definition \\
\hline TCP & $\begin{array}{l}\text { Daily total COVID-19 confirmed cases for country } i \text { at time } t \text { which is } \\
\text { measured as the daily cumulative number of COVID-19 confirmed cases } \\
\text { divided by country } i \text { total population }\end{array}$ \\
\hline GCHIgr & $\begin{array}{l}\text { Growth in Government Containment and Health Index for country } i \\
\text { between time } t \text { and time } t-1\end{array}$ \\
\hline GESIgr & $\begin{array}{l}\text { Growth in Government Economic Support Index for country } i \text { between } \\
\text { time } t \text { and time } t-1\end{array}$ \\
\hline$C 1$ & $\begin{array}{l}\text { Growth in the level of restrictions on school closures for country } i \text { at } \\
\text { time } t\end{array}$ \\
\hline$C 2$ & $\begin{array}{l}\text { Growth in the level of restrictions on workplaces closures for country } i \text { at } \\
\text { time } t\end{array}$ \\
\hline$C 3$ & Growth in the level of restrictions on public events for country $i$ at time $t$ \\
\hline$C 4$ & $\begin{array}{l}\text { Growth in the level of restrictions on cut-off size of public gathering for } \\
\text { country } i \text { at time } t\end{array}$ \\
\hline$C 5$ & $\begin{array}{l}\text { Growth in the level of restriction on public transport closures for country } \\
i \text { at time } t\end{array}$ \\
\hline C6 & $\begin{array}{l}\text { Growth in the level of restrictions on "stay-at-home" requirements for } \\
\text { country } i \text { at time } t\end{array}$ \\
\hline$C 7$ & $\begin{array}{l}\text { Growth in the level of restriction on internal travel between regions/cities } \\
\text { for country } i \text { at time } t\end{array}$ \\
\hline$C 8$ & $\begin{array}{l}\text { Growth in the level of restrictions on international travel for country } i \text { at } \\
\text { time } t\end{array}$ \\
\hline$H 1$ & $\begin{array}{l}\text { Growth in the level of public information campaigns for country } i \text { at time } \\
t\end{array}$ \\
\hline$H 2$ & $\begin{array}{l}\text { Growth in the level of government policy on testing policy for country } i \\
\text { at time } t\end{array}$ \\
\hline$H 3$ & $\begin{array}{l}\text { Growth in the level of government policy on contact tracing for country } i \\
\text { at time } t\end{array}$ \\
\hline H4 & $\begin{array}{l}\text { Growth in the level of government policy on the use of facial coverings } \\
\text { outside home for country } i \text { at time } t\end{array}$ \\
\hline H5 & $\begin{array}{l}\text { Growth in the level of government policy on protecting elderly people in } \\
\text { long term care facilities and/or the community and home setting for } \\
\text { country } i \text { at time } t\end{array}$ \\
\hline$H D I$ & Human development index of country $i$ \\
\hline $\ln (P D)$ & the natural logarithm of the population density of country $i$ \\
\hline$P D I$ & Level of power distance for country $i$ \\
\hline$I D V$ & Level of individualism versus collectivism for country $i$ \\
\hline$M A S$ & Level of masculinity versus femininity for country $i$ \\
\hline$U A I$ & Level of uncertainty avoidance index for country $i$ \\
\hline LTO & $\begin{array}{l}\text { Level of long-term orientation versus short-term normative orientation } \\
\text { for country } i\end{array}$ \\
\hline$I V R$ & Level of indulgence versus restraint for country $i$ \\
\hline
\end{tabular}


of 56 countries included in the study. Tightening of the containment and health measures has a significant and negative relationship with the growth in daily COVID-19 confirmed cases, emphasising the effectiveness of these two sets of measures. However, an increase in government economic support measures does not affect the growth in daily COVID-19 confirmed cases, although they may have other community benefits. Therefore, rest of this study will not include government economic support measures.

Table 3: Impact of government measures (containment and health measures - Model 1 and economic support measures - Model 2) on daily total COVID-19 confirmed cases over the period 22/01/2020-25/06/2021. The numbers in the parentheses are the robust standard errors. *, $* *$, and $* * *$ indicate significance at the $10 \%, 5 \%$, and $1 \%$ levels, respectively.

\begin{tabular}{|c|c|c|}
\hline & Model 1 & Model 2 \\
\hline Variable & TCP & TCP \\
\hline GCHIgr & $-0.0026^{* *}$ & \\
& $(0.0011)$ & \\
GESIgr & & -0.0004 \\
& & $(0.0009)$ \\
HDI & $0.4970^{* * *}$ & $0.4971 * * *$ \\
& $(0.0019)$ & $(0.0019)$ \\
Ln(PD) & $-0.8026^{* * *}$ & $-0.8022^{* * *}$ \\
& $(0.0031)$ & $(0.0029)$ \\
PDI & $0.1238^{* * *}$ & $0.1238^{* * *}$ \\
& $(0.0007)$ & $(0.0007)$ \\
IDV & $-0.1106^{* * *}$ & $-0.1107^{* * *}$ \\
& $(0.0002)$ & $(0.0002)$ \\
MAS & $0.0598^{* * *}$ & $0.0597 * * *$ \\
& $(0.0002)$ & $(0.0002)$ \\
UAI & $-0.1032^{* * *}$ & $-0.1033^{* * *}$ \\
& $(0.0005)$ & $(0.0005)$ \\
LTO & $-0.0431^{* * *}$ & $-0.0431^{* * *}$ \\
& $(0.0006)$ & $(0.0006)$ \\
IVR & $-0.0278^{* * *}$ & $-0.0279^{* * *}$ \\
& $(0.0013)$ & $(0.0013)$ \\
Constant & $-3.6305^{* * *}$ & $-3.647221^{* * *}$ \\
& $(0.9460)$ & $(0.9554)$ \\
\hline Countryeffect & Yes & Yes \\
Day effect & Yes & Yes \\
Observations & 27,403 & 27,403 \\
\hline
\end{tabular}

The study now explores the impact of component policies of the Government Containment and Health Index on growth in daily COVID-19 confirmed cases. Table 4 shows the results of this analysis by estimating eqn (2) using the two-way cluster pooled panel OLS regression. The Government Containment and Health Index comprises eight measures of containment actions (denoted by $C 1$ to $C 8$ ) and five measures of health-related actions (denoted by $\mathrm{Hl}$ to $H 5$ ). This analysis is undertaken first for the full set of 56 countries included in the study. Then the study explores whether the findings will hold if we segment our sample into high income countries, upper-middle income countries and lower-middle 
Table 4: The effect of government containment and health-related intervention policies on the COVID-19 total confirmed cases in aggregate and in high, upper-middle and lower-middle income countries. The numbers in the parentheses are the robust standard errors. $*, * *$, and $* * *$ indicate significance at the $10 \%, 5 \%$, and $1 \%$ levels, respectively.

\begin{tabular}{|c|c|c|c|c|}
\hline & All countries & $\begin{array}{l}\text { High income } \\
\text { countries }\end{array}$ & $\begin{array}{c}\text { Upper-middle income } \\
\text { countries }\end{array}$ & $\begin{array}{l}\text { Lower-middle } \\
\text { income countries }\end{array}$ \\
\hline Variables & TCP & TCP & TCP & TCP \\
\hline$C 1$ & $\begin{array}{c}-0.2319^{* * *} \\
(0.0784)\end{array}$ & $\begin{array}{c}-0.2759^{* *} \\
(0.1177)\end{array}$ & $\begin{array}{c}-0.2433^{* * *} \\
(0.0825)\end{array}$ & $\begin{array}{c}-0.1065^{* *} \\
(0.0499)\end{array}$ \\
\hline$C 2$ & $\begin{array}{l}-0.1494 \\
(0.0753)\end{array}$ & $\begin{array}{l}-0.0908 \\
(0.1007)\end{array}$ & $\begin{array}{c}-0.1663 * * \\
(0.0714)\end{array}$ & $\begin{array}{l}-0.0591 \\
(0.0513)\end{array}$ \\
\hline$C 3$ & $\begin{array}{c}-0.2466^{* *} \\
(0.1029)\end{array}$ & $\begin{array}{c}-0.2826^{*} \\
(0.1577)\end{array}$ & $\begin{array}{c}-0.3563 * * * \\
(0.1156)\end{array}$ & $\begin{array}{l}-0.0346 \\
(0.0835)\end{array}$ \\
\hline C4 & $\begin{array}{c}-0.1874 * * * \\
(0.0550)\end{array}$ & $\begin{array}{c}-0.3278 * * * \\
(0.0984)\end{array}$ & $\begin{array}{c}-0.1121 * * \\
(0.0553)\end{array}$ & $\begin{array}{l}-0.0393 \\
(0.0502)\end{array}$ \\
\hline C5 & $\begin{array}{c}0.0427 \\
(0.0914)\end{array}$ & $\begin{array}{c}0.0148 \\
(0.2244)\end{array}$ & $\begin{array}{l}-0.1117 \\
(0.0851)\end{array}$ & $\begin{array}{l}0.0016 \\
(0.0482)\end{array}$ \\
\hline C6 & $\begin{array}{l}-0.0232 \\
(0.0634)\end{array}$ & $\begin{array}{c}-0.2699^{* *} \\
(0.1289)\end{array}$ & $\begin{array}{l}-0.0213 \\
(0.0673)\end{array}$ & $\begin{array}{c}0.0998 \\
(0.0764)\end{array}$ \\
\hline$C 7$ & $\begin{array}{l}-0.0542 \\
(0.0647)\end{array}$ & $\begin{array}{l}-0.0942 \\
(0.1316)\end{array}$ & $\begin{array}{l}-0.0317 \\
(0.0758)\end{array}$ & $\begin{array}{c}-0.0632 * * \\
(0.0275)\end{array}$ \\
\hline$C 8$ & $\begin{array}{c}-0.1953 * * * \\
(0.0589)\end{array}$ & $\begin{array}{c}-0.2219^{* *} \\
(0.1001)\end{array}$ & $\begin{array}{l}-0.1190 \\
(0.0991)\end{array}$ & $\begin{array}{c}-0.0650 * * \\
(0.0268)\end{array}$ \\
\hline$H 1$ & $\begin{array}{l}-0.0748 \\
(0.1462)\end{array}$ & $\begin{array}{c}0.0404 \\
(0.4057)\end{array}$ & $\begin{array}{l}-0.1955 \\
(0.1660)\end{array}$ & $\begin{array}{c}-0.1063 * \\
(0.0631)\end{array}$ \\
\hline$H 2$ & $\begin{array}{l}-0.1610 \\
(0.1089)\end{array}$ & $\begin{array}{c}-0.4684 * * * \\
(0.1544)\end{array}$ & $\begin{array}{l}-0.0452 \\
(0.0895)\end{array}$ & $\begin{array}{l}0.1095 \\
(0.0704)\end{array}$ \\
\hline$H 3$ & $\begin{array}{c}-0.3856^{* * *} * \\
(0.1219)\end{array}$ & $\begin{array}{c}0.0499 \\
(0.2623)\end{array}$ & $\begin{array}{c}-0.5818^{* * * *} \\
(0.1576)\end{array}$ & $\begin{array}{c}-0.2446^{* *} \\
(0.0990)\end{array}$ \\
\hline H4 & $\begin{array}{c}-0.2542^{* * *} \\
(0.0789)\end{array}$ & $\begin{array}{c}-0.6505^{* * *} \\
(0.1847)\end{array}$ & $\begin{array}{c}-0.2554 * * * \\
(0.0595)\end{array}$ & $\begin{array}{l}-0.0644 \\
(0.0409)\end{array}$ \\
\hline H5 & $\begin{array}{c}-0.2173 * * * \\
(0.0583)\end{array}$ & $\begin{array}{c}-0.4588^{* * *} \\
(0.1113)\end{array}$ & $\begin{array}{l}-0.0478 \\
(0.0712)\end{array}$ & $\begin{array}{l}-0.1225 \\
(0.1008)\end{array}$ \\
\hline$H D I$ & $\begin{array}{c}0.0512 * * * \\
(0.0199)\end{array}$ & $\begin{array}{c}0.0449 \\
(0.0777)\end{array}$ & $\begin{array}{l}0.0621^{* *} \\
(0.0299)\end{array}$ & $\begin{array}{c}0.0127 \\
(0.0189)\end{array}$ \\
\hline $\operatorname{Ln}(P D)$ & $\begin{array}{c}0.1062 \\
(0.1163)\end{array}$ & $\begin{array}{c}0.2517 \\
(0.1984)\end{array}$ & $\begin{array}{c}0.1458 \\
(0.1425)\end{array}$ & $\begin{array}{c}0.0470 * * \\
(0.0607)\end{array}$ \\
\hline$P D I$ & $\begin{array}{c}0.0002 \\
(0.0076)\end{array}$ & $\begin{array}{c}0.0053 \\
(0.0118)\end{array}$ & $\begin{array}{c}-0.0234 * * * \\
(0.0082)\end{array}$ & $\begin{array}{c}-0.0135^{*} \\
(0.0071)\end{array}$ \\
\hline$I D V$ & $\begin{array}{l}0.0188^{* *} \\
(0.0094)\end{array}$ & $\begin{array}{l}0.0253^{*} \\
(0.0142)\end{array}$ & $\begin{array}{c}0.0090 \\
(0.0116)\end{array}$ & $\begin{array}{c}0.0237 * * * \\
(0.0060)\end{array}$ \\
\hline$M A S$ & $\begin{array}{l}-0.0139^{*} \\
(0.0081)\end{array}$ & $\begin{array}{c}-0.0197 * * * \\
(0.0073)\end{array}$ & $\begin{array}{l}-0.0143 \\
(0.0106)\end{array}$ & $\begin{array}{l}0.0078 \\
(0.0236)\end{array}$ \\
\hline$U A I$ & $\begin{array}{c}0.0171 * * \\
(0.0068)\end{array}$ & $\begin{array}{l}-0.0018 \\
(0.0102)\end{array}$ & $\begin{array}{c}0.0222 * * * \\
(0.0084)\end{array}$ & $\begin{array}{c}0.0360^{* * *} * \\
(0.0090)\end{array}$ \\
\hline LTO & $\begin{array}{l}-0.0076 \\
(0.0079)\end{array}$ & $\begin{array}{l}-0.0033 \\
(0.0143)\end{array}$ & $\begin{array}{c}-0.0232 * * * \\
(0.0080)\end{array}$ & $\begin{array}{c}-0.0148^{* * *} \\
(0.0045)\end{array}$ \\
\hline$I V R$ & 0.0001 & -0.0147 & -0.0125 & $0.0287^{* * *} *$ \\
\hline Constant & $\begin{array}{c}-3.6600^{* *} \\
(1.5517)\end{array}$ & $\begin{array}{c}5.8323 \\
(6.6531)\end{array}$ & $\begin{array}{l}-1.5368 \\
(2.8746)\end{array}$ & $\begin{array}{l}-4.1153^{*} \\
(2.3601)\end{array}$ \\
\hline $\begin{array}{c}\text { Observations } \\
\text { Prob }>F\end{array}$ & $\begin{array}{l}27,403 \\
0.0000\end{array}$ & $\begin{array}{l}12,350 \\
0.0000\end{array}$ & $\begin{array}{l}10,160 \\
0.0000\end{array}$ & $\begin{array}{c}4,893 \\
0.0000\end{array}$ \\
\hline
\end{tabular}


income countries. The rationale for this segmentation includes differences in economic conditions, healthcare system capabilities, educational levels and national cultures of countries belonging to these three categories.

\subsection{Effect of containment measures}

The results presented in Table 4 show that there are major differences among the three categories of countries in how the growth in daily COVID-19 confirmed cases responds to different government containment actions. Four containment measures - level of restrictions relating to school closures, conducting public events, the size of public gathering and international travel - have a significant negative relationship with the growth in daily COVID-19 confirmed cases when data are pooled together for all countries. However, the level of restrictions relating to school closures is the only containment measure which decreases daily COVID-19 confirmed cases across all the three country classifications. Restrictions on conducting public events and on the size of public gathering are effective in decreasing daily COVID-19 confirmed cases in high income countries and upper-middle income countries. Restrictions on international travel are an effective mitigant against increase in daily COVID-19 confirmed cases in high income countries and lower-middle income countries. Restrictions relating to public transport closures is the only containment measure which does not have a relationship with daily COVID-19 confirmed cases either in the pooled sample or any of the country categories. Although not observed in the pooled sample of all country categories, the following containment measures decrease growth in infections in specific country categories - stay at home restrictions in high income countries, restrictions on workplace closures in upper-middle income countries and restrictions on travel between regions and cities in lower-middle income countries.

It is a key finding from this study that the effectiveness of containment measures is related to the economic context of the countries. In Table 4, we note that in lower-middle income countries, only three containment measures have a significant negative relationship with the growth in daily COVID-19 confirmed cases whereas corresponding numbers for high income countries and upper-middle income countries are five and four respectively. Limited economic resources to implement the containment measures, weak governance and poor compliance regimes are possible explanations for the lower effectiveness of containment measures in lower-middle income countries [3], [18].

\subsection{Effect of health measures}

Results in Table 4 also show that there are key differences among the three categories of countries in how the five health-related measures impact growth in daily COVID-19 confirmed cases. When data are pooled together for all countries, three component policies - level of contact tracing, level of restrictions on the use of facial coverings outside home and level of protection for elderly people in long term care facilities and/or the community and home setting - help to slow the growth in infections. However, none of these three measures has any significant effect on infections in any of the three country classifications. Level of government policy on testing, level of requirements for the use of facial coverings outside home and level of protection for elderly people help to decrease the infections in high income countries. Contact tracing and the use of facial coverings outside home are helpful in curtailing infections in upper-middle income countries. Public information campaigns and contact tracing are the only health measures that seem to suppress infections in the lowermiddle income countries. 


\subsection{Effect of national culture}

The study finds that national culture of countries, measured by the six Hofstede cultural dimensions, has a major relationship with the spread of COVID-19. The direction of the relationships varies depending on the individual dimension. Table 5 summaries the inferences from Table 4 relating to these relationships.

Table 5: Relationship between growth in daily COVID-19 confirmed cases and six Hofstede cultural dimensions in aggregate and in high income, upper-middle income and lower-middle income countries.

\begin{tabular}{|c|c|c|}
\hline $\begin{array}{l}\text { Hofstede cultural dimension } \\
\text { index }\end{array}$ & $\begin{array}{l}\text { Nature of } \\
\text { relationship with } \\
\text { growth in daily } \\
\text { COVID-19 } \\
\text { confirmed cases }\end{array}$ & Applicable country categories \\
\hline $\begin{array}{l}\text { Individualism versus } \\
\text { collectivism }\end{array}$ & Positive & $\begin{array}{l}\text { All countries } \\
\text { High income countries } \\
\text { Lower-middle income countries } \\
\text { All countries }\end{array}$ \\
\hline Uncertainty avoidance & Positive & $\begin{array}{l}\text { Upper-middle income countries } \\
\text { Lower-middle income countries }\end{array}$ \\
\hline Masculinity versus femininity & Negative & $\begin{array}{l}\text { All countries } \\
\text { High income countries }\end{array}$ \\
\hline Power distance & Negative & $\begin{array}{l}\text { Upper-middle income countries } \\
\text { Lower-middle income countries }\end{array}$ \\
\hline $\begin{array}{l}\text { Long-term versus short-term } \\
\text { normative orientation }\end{array}$ & Negative & $\begin{array}{l}\text { Upper-middle income countries } \\
\text { Lower-middle income countries }\end{array}$ \\
\hline Indulgence versus restraint & Positive & Lower-middle income countries \\
\hline
\end{tabular}

Table 5 shows that three Hofstede cultural dimensions (individualism versus collectivism, uncertainty avoidance, and indulgence versus restraint) are positively related to growth in daily COVID-19 confirmed cases, whereas the other three (masculinity versus femininity, power distance, and long-term versus short-term normative orientation) are negatively related. Effectiveness of response to a pandemic requires collective effort of the communities and it should not be surprising that in individualism-dominant countries where people's selfimage is defined by "I" rather than "we", it is harder to control COVID-19 infections. Countries with high uncertainty avoidance display more resistance to change accepted norms of behaviour. By not quickly making necessary changes to behaviour such as social distancing, these communities may struggle to contain COVID-19 infections. High scores on indulgence versus restraint denote a society which allows free gratification of natural human drives to enjoy life. Such social disposition can be expected to impede efforts to curtail spread of COVID-19 infections as evident from the positive relationship. Societies where the dominant cultural trait is masculinity are more assertive and achievement focussed and are not consensus oriented. Crisis events such as the pandemic call for decisive actions and therefore, the negative relationship shown in Table 5 for masculinity versus femininity index seems justified. High power distance in a country setting means people accept hierarchical order readily and such acceptance can be helpful when major changes in social behaviour are 
to be implemented rapidly during the course of a pandemic. Societies which have high longterm versus short-term normative orientation do not hold on to time-honoured traditions and nor do they view social changes with suspicion. Such a cultural orientation facilitates implementation of big changes necessary to bring down infection rates.

An important finding from our research is that national culture has a greater influence in lower-middle income countries in determining the effectiveness of measures to control the spread of COVID-19. Table 4 shows that five of the six Hofstede cultural dimensions have significant relationships with the growth in daily COVID-19 confirmed cases in lowermiddle income countries, whereas corresponding numbers for high income countries and upper-middle income countries are three each. It seems that relatively weak economic strength, health infrastructure, governance structure and technological capability of the lower-middle income countries provide national culture a profound role in determining the success of these countries in their fight against the pandemic [19], [20].

\subsection{Effect of other contextual variables}

The study now examines results in Table 4 for the relationship of growth in daily COVID19 confirmed cases with Human Development Index and population density in the countries. Human Development Index is positively related to growth in daily COVID-19 confirmed cases when data are pooled together for all countries and in the category of upper-middle income countries. This positive association is consistent with literature [12], [13], [21] and it may be attributed to higher risk of COVID-19 infection of populations in upper-middle income countries due to their longer life expectancy. The absence of such association in high income countries, despite their longer life expectancy, may be ascribed to better healthcare infrastructure in these countries. In addition to shorter life expectancy, under-reporting of COVID-19 cases due to limited capacity for testing may explain the absence of positive association between Human Development Index and growth in daily COVID-19 confirmed cases in lower-middle income countries [12]. In lower-middle income countries we find a positive relationship between growth in daily COVID-19 confirmed cases and population density. Weak healthcare infrastructure and less rigorous compliance with COVID-19 control measures may explain this association.

\section{CONCLUSION}

This study investigates effectiveness of country responses in controlling the spread of COVID-19 pandemic. Government responses are first grouped into Containment and Health Index and Economic Support Index. The investigation is based on the belief that the effectiveness of these responses is conditioned by the context in which they are implemented. The study, therefore, explores their effectiveness separately for high income countries, uppermiddle income countries and lower-middle income countries. In addition to the economic context defined by the above country categories, we further explore whether other contextual variables, namely national culture, level of human development, and population density influence the effectiveness of the measures to combat the spread of COVID-19.

The research shows that, overall, the set of containment and health measures are effective in curtailing the growth of daily COVID-19 confirmed cases, but economic support measures are not effective. However, there are major differences in the usefulness of containment and health measures depending on the economic context of the countries. This calls for tailoring the responses of governments to the economic context of individual countries. For example, containment measures are less successful in lower-middle income countries compared to the other two categories of countries. Given the resource constraints and weaknesses in 
governance and compliance regimes in lower-middle income countries, it may be worthwhile for policy makers in these countries to customise their actions based on the findings presented in this paper.

National cultural traits have varying degrees of influence in supporting or hindering successful outcomes of the measures undertaken to decrease COVID-19 infections. The finding that low levels of individualism versus collectivism, uncertainty avoidance, and indulgence versus restraint and high levels of masculinity versus femininity, power distance, and long-term versus short-term normative orientation contribute to decrease in infections is useful to government policy makers and health management experts in designing suitable responses to fight the pandemic. Far greater influence of national culture in shaping successful policy outcomes in lower-middle income countries points to devoting special attention to cultural sensitivities when designing and implementing strategies to manage the pandemic in these countries.

COVID-19 pandemic has imposed unprecedented human and economic costs on almost all countries. Developing effective containment and health policies is of paramount importance to manage the disaster. This research contributes to existing literature in helping to develop these policies. It shows that it is imperative to tailor the policy mix of countries to achieve optimal outcomes in managing the pandemic. Since the fight against the pandemic is seriously constrained by resource availability, especially in lower-middle income countries, prioritising implementation of effective policies is critical. Our research assists in this prioritisation by taking into account the economic, cultural and human development contexts of individual countries. A topic for future research is the effect of COVID-19 vaccinations on infection and fatality rates and how the contextual variables used in this study affect these relationships.

\section{REFERENCES}

[1] Oxford COVID-19 Government Response Tracker. https://www.bsg.ox.ac.uk/ research/research-projects/covid-19-government-response-tracker. Accessed on: 12 Jun. 2021.

[2] Report of the WHO-China Joint Mission on Coronavirus Disease 2019 (COVID-19). https://www.who.int/docs/default-source/coronaviruse/who-china-joint-mission-oncovid-19-final-report.pdf?sfvrsn=fce87f4e_2. Accessed on: 15 Jul. 2021.

[3] Zaremba, A., Kizys, R., Aharon, D.Y. \& Demir, E., Infected markets: Novel coronavirus, government interventions, and stock return volatility around the globe. Finance Research Letters, 2020.

[4] Huynh, T.L., Does culture matter social distancing under the COVID-19 pandemic? Safety Science, 2020.

[5] Brauner J.M. et al., Inferring the effectiveness of government interventions against COVID-19. Science (American Association for the Advancement of Science), 2021.

[6] Wang, Y., Government policies, national culture and social distancing during the first wave of the COVID-19 pandemic: International evidence. Safety Science, 2021.

[7] Chisadza, C., Clance, M. \& Gupta, R., Government effectiveness and the COVID-19 pandemic. Sustainability (Basel, Switzerland), 2021.

[8] Hofstede, G., Dimensionalizing cultures: The Hofstede model in context. Online Readings in Psychology and Culture, 2011.

[9] Pham, N.C., Li, Y., Schapsis, C., Hossain, T., Pham, H.H., Fischer, D. \& Yang, J., Intrinsic cultural factors that helped Vietnam overcome the COVID-19 pandemic compared with other countries. Asia Pacific Journal of Health Management, 2020. 
[10] Sun, Z., Zhang, H., Yang, Y., Wan, H. \& Wang, Y., Impacts of geographic factors and population density on the COVID-19 spreading under the lockdown policies of China. Science of The Total Environment, 2020.

[11] Velasco, J.M., Tseng, W.C. \& Chang, C.L., Factors affecting the case and deaths of COVID-19 victims. International Journal of Environmental Research and Pacific Health, 2021.

[12] António, N., Rita, P. \& Saraiva, P., COVID-19: Worldwide profiles during the first 250 days. Applied Sciences, 2021.

[13] Liu, J.H., Majority world successes and European and American failure to contain COVID-19: Cultural collectivism and global leadership. Asian Journal of Social Psychology, 2021.

[14] DataStream database. Refinitiv Datastream. Available online from a subscription service. Accessed on: 12 Jun. 2021.

[15] Hofstede Insights. https://www.hofstede-insights.com/. Accessed on: 12 Jun. 2021.

[16] Our World in Data database. https:/github.com/owid/covid-19-data/tree/master/ public/data. Accessed on: 12 Jun. 2021.

[17] New World Bank, Country classifications by income level: 2020-2021. https://blogs.worldbank.org/opendata/new-world-bank-country-classificationsincome-level-2020-2021. Accessed on: 12 Jun. 2021.

[18] Engelhardt, N., Krause, M., Neukirchen, D. \& Posch, P.N., Trust and stock market volatility during the COVID-19 crisis. Finance Research Letters, 2021.

[19] Islam, S.N., Cheng, H.J., Helgason, K.S., Hunt, N., Kawamura, H. \& Lafleur, M., Variations in COVID strategies: Determinants and lessons. United Nations, 2020.

[20] Gupta, M., Shoja, A. \& Mikalef, P., Toward the understanding of national culture in the success of non-pharmaceutical technological interventions in mitigating COVID19 pandemic. Annals of Operations Research, 2021.

[21] Khazaei, Z., Goodarzi, E., Naemi, H., Hasanpour-Dehkordi, A. \& NaghibzadehTahami, A., COVID-19 pandemic in the world and its relation to Human Development Index: A global study. Archives of Clinical Infectious Diseases, 2020. 